\title{
Scion-rootstock relationships in Hybrid Tea cut roses on Rosa canina 'Inermis'
}

\author{
D. P. de Vries and Lidwien A. M. Dubois
}

Institute for Horticultural Plant Breeding (IVT), P.O. Box 16, 6700 AA

Wageningen, Netherlands

Received 8 April 1983; accepted 5 August 1983

Key-words: Rosa, rose, Hybrid Tea, 'Inermis', rootstock, shoot yield, girth, bottom-break, aerial part, underground part, equilibrium, scion dominance

\section{Summary}

In 2 successive years, batches of 11-month-old cut rose clones were uprooted in December. Highly significant correlations occurred between the girth at the graft union and the root weight or the number of bottom-breaks, between the root weight and the number of bottom-breaks, and between the number of bottombreaks and the number of harvested shoots. Plant vigour in clones was mainly determined by the scion. Rootstock-scion relations in rose and fruit are compared. The equilibrium between aerial and underground parts in composite plants is discussed. Breeding of rose rootstocks that promote scion vigour under various glasshouse conditions is recommended.

\section{Introduction}

Glasshouse roses on a rootstock are composite plants, the shoots of which are harvested ('pruned') when about ripe to flower. For this industry, only a few rootstocks are available. In the Netherlands, mainly seed-propagated Rosa canina selections are used, among which the cultivar 'Inermis' has a leading position (van Marsbergen, 1983).

Comparison of the relative vigour of Hybrid Tea roses on their own roots and on 'Inermis' stocks showed that the highly significant correlation between the number of bottom-breaks and of harvested shoots in own-rooted seedlings was of the same magnitude when the plants were grafted on 'Inermis' (de Vries \& Dubois, 1983). Although 'Inermis' tended somewhat to smooth out differences between low-yielding and high-yielding clones, its overall effect on vigour, as measured by the aerial parts, was negligible. Effects of difference in clonal vigour on the growth of underground parts have not yet been investigated.

Our present paper deals with the relations between on the one hand the sub-soil parts: girth and root weight, and on the other the aerial parts: number of bottom- 
breaks and of harvested shoots, of 11-month-old cut rose clones on R.canina 'Inermis'.

\section{Materials and methods}

In January 1979 and 1980, different batches of 71 and 52 Hybrid Tea rose seedlings respectively, selected for glasshouse properties, were rind-grafted onto R.canina 'Inermis' stocks. Ten plants of each clone were planted in a rose house. At the end of each year, when they were about 11 months old, plants were uprooted, and cut through the graft union. The following data were recorded:

- the individual fresh weight of 100 stocks, to be used for grafting in 1979;

- the number of shoots (flowering and blind) per clone;

- the number of bottom-breaks,

- the root collar diameter ('girth') at the graft union,

- the fresh weight of the sub-terranean part ('root weight') of each plant.

\section{Results}

Girth, root weight, number of bottom-breaks and number of harvested shoots per clone varied insignificantly between the two years (Table 1). Compared with the initial root weight $(13.0 \pm 3.6 \mathrm{~g})$ stocks in an about one-year growing season increased approximately 2.5 times in weight.

Table 2 shows highly significant interclonal correlations between girth and root weight and between girth and number of bottom-breaks; these relations are illustrated in Fig. 1. As could be expected (Table 1), the regression for the 2 years did not differ significantly. Correlations between girth and number of shoots were not significant. Table 2 also shows highly significant correlations between root weight and number of bottom-breaks, and between number of bottom-breaks and number of shoots (see also de Vries \& Dubois, 1983). Correlations between root weight and number of shoots were insignificantly low.

Within clones also, correlations occurred between girth and root weight $(0.54 \leqslant r$ $\leqslant 0.92, n=10)$, between girth and the number of bottom-breaks $(0.42 \leqslant r \leqslant 0.92, n$ $=10)$ and between root weight and number of bottom-breaks $(0.25 \leqslant r \leqslant 0.83, n=$ $10)$. As between clones, the latter association was weakest and significant in a few clones only.

Table 1. Girth, root weight, number of bottom-breaks and number of shoots harvested in 11-month-old cut rose clones on R.canina 'Inermis', in 1979 and 1980.

\begin{tabular}{lcc}
\hline Characteristics & $1979(n=71)$ & $1980(n=52)$ \\
Girth (mm) & $21.2 \pm 2.2$ & $20.8 \pm 1.8$ \\
Root weight $(\mathrm{g})$ & $32.1 \pm 6.3$ & $30.0 \pm 5.3$ \\
Number of bottom-breaks & $2.3 \pm 0.5$ & $1.8 \pm 0.3$ \\
Number of shoots harvested & $13.2 \pm 3.9$ & $11.6 \pm 4.4$ \\
\hline
\end{tabular}


Table 2. Interclonal correlations between the girth, the root weight, the number of bottom-breaks and the number of harvested shoots in 11-month-old cut rose clones on R.canina 'Inermis', in 1979 and 1980.

\begin{tabular}{llll}
\hline Relation & & $1979(n=71)$ & $1980(n=52)$ \\
Girth & - Root weight & 0.70 & 0.76 \\
& - Number of bottom-breaks & 0.57 & 0.62 \\
& - Number of shoots & n.s. & n.s. \\
Root weight & - Number of bottom-breaks & 0.35 & 0.39 \\
& - Number of shoots & n.s. & n.s. \\
Number of bottom-breaks & - Number of shoots & 0.49 & 0.50 \\
& & $P=0.01, r \geqslant 0.30$ & $P=0.01, r \geqslant 0.35$ \\
\hline
\end{tabular}
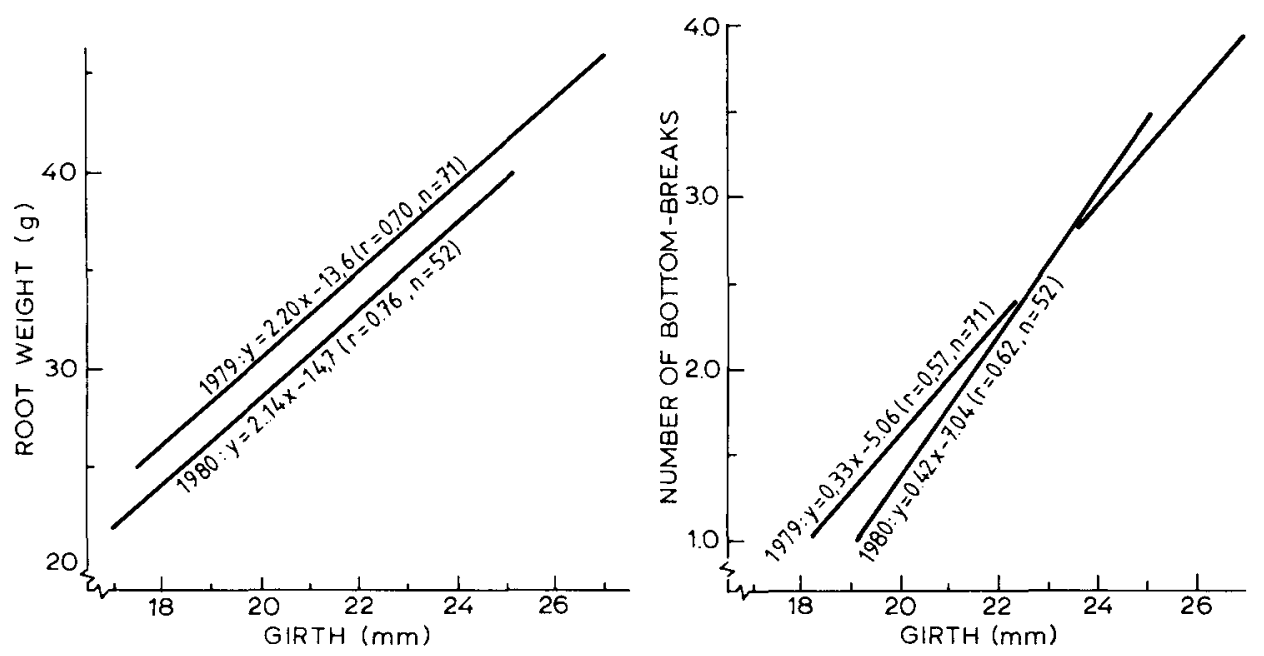

Fig. 1. The relation between girth and root weight (left) and girth and number of bottom-breaks (right), in 11-month-old cut rose clones on R.canina 'Inermis'.

\section{Discussion and conclusions}

The results demonstrate close relations between the aerial and sub-soil parts of cut rose clones on 'Inermis'. These relations, which hold both between and within clones, show great similarity to those in deciduous fruit crops. For instance, between 'Sweet Cherry' cultivars on F12/1 rootstock, crown volume, trunk girth and root system are very closely correlated (Maurer, 1971), and within apple clones the weights of root, stock, trunk, branch and of accumulated prunings are also very significantly correlated (Moore, 1978).

In general, in plants that are regularly pruned, either as a cultural measure of for experimental purpose, a kind of equilibrium between aerial and underground parts, characteristic for the conditions prevailing seems to be reached (Brouwer, 1963; Visser, 1969; Wareing, 1970). Present results confirm such an equilibrium for 
cut rose clones of different vigour, on the rootstock 'Inermis'. As vigorous clones are much more frequently harvested than weak ones, this equilibrium means that total regrowth is much better in vigorous than in weak clones. Because the relative vigour of own-rooted seedlings was not affected when they were grafted onto 'Inermis' (de Vries \& Dubois, 1983), the above equilibrium also shows that the vigour of a composite rose plant is mainly determined by the scion.

This scion dominance is probably one of the reasons for the popularity of 'Inermis' to breeders, because after grafting previously selected seedlings, they recognize about the same vigour in their clones.

With regard to vigour of composite woody plants, it is of interest to consider experimental results in apple. Contrary to roses, variation in apple rootstock vigour is large compared with that of the scion (Moore, 1975). There is evidence that main vigour of the scion is determined by the roots (Moore, 1975), probably by cytokinin-like substances (Jones, 1973) reacting in the shoots with auxins produced there. In cut roses also, where apical dominance (Zieslin et al., 1979) benefits the formation of the desired straight, unbranched shoots, it was shown that the antagonism between auxins and cytokinins (Carpenter \& Rodriguez, 1971) plays an important role in the number of bottom-breaks formed.

De Vries \& Dubois (1983) found that plants with a low number of bottom-breaks in the seedling stage had a somewhat higher number in the clonal stage but, as the number of bottom-breaks in seedlings was higher (and hence the flower production), the number of bottom-breaks in their clones did not increase correspondingly. They suggested that in highly productive own-rooted seedlings, substituting 'Inermis' for the seedling's own roots, resulted in a relative lack of cytokinins, and hence in a lower clonal flower yield.

In practice, this means that the properties of 'Inermis', and probably of any currently available rootstock, are insufficient to meet the growers' demand for higher flower production. It is thus desirable to select and/or breed a series of rootstocks that efficiently controls scion vigour. Contrary to fruit growing, in which controlling usually means a combination of reduced vigour, precocity and productivity, in roses controlling should mean: highest possible vigour, the ability to stand continuous harvesting (pruning) of the scion, and the ability to perform well under different environmental conditions.

Analysis of rootstock sap for cytokinin activity (Jones, 1973) in this selection procedure is advisable.

\section{References}

Brouwer, R., 1963. Some aspects of the equilibrium between overground and underground plant parts. Jaarboek, Instituut voor Scheikundig en Biologisch Onderzoek van Landbouwgewassen, pp. 31-39.

Carpenter, W. J. \& R. C. Rodriguez, 1971. The effect of plant growth regulating chemicals on rose shoot development from basal and axillary buds. Journal of the American Society for Horticultural Science $96: 389-391$.

Jones, O. P., 1973. Effects of cytokinins in xylem sap from apple trees on apple shoot growth. Journal of Horticultural Science 48: 181-188.

Marsbergen, W. van, 1983. Keuze onderstam bij kasrozenteelt erg belangrijk. Vakblad Bloemisterij 2 : 39. 
Maurer, K. J., 1971. Untersuchungen der Beziehungen zwischen dem Kronenvolumen und dem Umfang des Wurzelsystems bei Süsskirschbäumen. Mitteilungen Klosterneuburg 21(2): 139-142.

Moore, C. S., 1975. Relative importance of rootstock and scion in determining growth and fruiting in young apple trees. Annals of Botany 39: 113-123.

Moore, C. S., 1978. Biometrical relationships in apple trees. Journal of Horticultural Science 53: 45-51.

Visser, T., 1969. The effect of root and shoot damage on the growth of tea plants. Netherlands Journal of Agricultural Science 17: 234-240.

Vries, D. P. de \& Lidwien A. M. Dubois, 1983. Relations between bottom-breaks and harvested shoots in own-rooted Hybrid Tea-rose seedlings and their clones. Gartenbauwissenschaft 48: 189-192.

Wareing, P. F., 1970. Growth and its co-ordination in trees. In: L. C. Luckwill \& C. V. Cutting (Eds.), Physiology of tree crops. Proceedings 2nd Long Ashton Symposium (1969). Academic Press, London/New York.

Zieslin, N., Y. Mor, A. Bachrach, H. Haaze \& A. M. Kofranek, 1976. Controlling the growth and development of rose plants after planting. Scientia Horticulturae 4: 63-72. 